\title{
Six novel mutations detected in the GALC gene in 17 Japanese patients with Krabbe disease, and new genotype-phenotype correlation
}

Received: 24 November 2005 / Accepted: 18 February 2006/Published online: 11 April 2006

(C) The Japan Society of Human Genetics and Springer-Verlag 2006

\begin{abstract}
Krabbe disease is an autosomal recessive leukodystrophy. It is pathologically characterized by demyelination of the central and peripheral nervous systems and the accumulation of globoid cells in brain white matter. It is caused by a deficiency of galactocerebrosidase (GALC) activity. We investigated mutations of the GALC gene in 17 Japanese patients with Krabbe disease, the largest subject number of Japanese patients to date, and found 27 mutations. Of these mutations, six were novel, including two nonsense mutations, W115X and R204X, two missense mutations, S257F and L364R, a small deletion, 393delT, and a small insertion, 1719-1720insT. Our findings, taken with the reported mutations in Japanese patients, confirm several mutations common to Japanese patients, the two most frequent being 12Del3Ins and I66M + I289V, which account for $37 \%$ of all mutant alleles. With two additional mutations, G270D and T652P, these account for up to $57 \%$ of genetic mutations in Japanese patients. Distribution of the mutations within the GALC gene indicated some genotype-phenotype correlation. $\mathrm{I} 66 \mathrm{M}+\mathrm{I} 289 \mathrm{M}, \mathrm{G} 270 \mathrm{D}$, and L618S contributed to a mild phenotype. Screening for these mutations may provide an effective method with which to predict the clinical phenotype.
\end{abstract}

Keywords Globoid cell leukodystrophy ·

Krabbe disease - Galactocerebrosidase ·

Mutation analysis - Genotype-phenotype correlation

\section{Introduction}

Krabbe disease (globoid cell leukodystrophy: GLD, MIM 245200) is an autosomal recessive neurodegenerative disorder caused by a deficiency of galactocerebrosidase (GALC) (EC 3.2.1.46). It was first reported by Krabbe (1916) under the title "A new familial, infantile form of diffuse brain sclerosis". Approximately $90 \%$ of patients have the early infantile form, first manifesting symptoms before 6 months old and experiencing rapid disease progression over the ensuing 1 or 2 years (Wenger et al. 2001). The remaining 10\% have late-onset Krabbe disease and are classified into one of three classes, late-infantile type, juvenile type, or adult type, depending on the onset period and the rate of progression of the disease. Molecular cloning of the human GALC gene by Chen et al. (1993) (GenBank Accession No. L23116) and Sakai et al. (1994) (GenBank Accession No. L38544, L38559), has led to molecular-level analyses of Krabbe disease.

More than 60 GALC mutations, all with molecular heterogeneity, have been reported worldwide (Wenger et al. 1997). Whereas several papers (Tatsumi et al. 1995; Furuya et al. 1997; Kukita et al. 1997-98; Satoh et al. 1997; $\mathrm{Fu}$ et al. 1999) have reported Krabbe disease mutations in Japanese patients, clear genotype-phenotype correlations remain obscure, because of the small number of subjects studied. We evaluated the GALC gene in 17 Japanese patients, classifying mutations according to clinical phenotype. Here, we report the common mutations and the correlation between such mutations and their clinical severity.

\section{Materials and methods}

Patients

We studied 17 unrelated Japanese patients with Krabbe disease, originating from different regions of Japan.
Department of Pediatrics,

Osaka University Graduate School of Medicine,

2-2 Yamadaoka, Suita, Osaka 565-0871, Japan

E-mail: norio@ped.med.osaka-u.ac.jp

Tel.: + 81-6-68793935

Fax: + 81-6-68793939 
There were no consanguineous marriages between the patients' parents. The subjects included three (patients $\mathrm{A} 1, \mathrm{~A} 2$, and A13) included in a previous study who were shown to have only one single mutant allele. The clinical information is summarized in Table 1. Diagnoses were determined in our laboratory as reduced GALC activity in either fibroblasts or leukocytes, and by other characteristic clinical and laboratory findings. According to the age at onset, patients were classified into one of four clinical phenotype groups: infantile onset, aged up to 6 months, nine patients; late-infantile onset, 7 months to 2 years, two patients; juvenile onset, 3-8 years, four patients; and adult onset, over 9 years, two patients.

\section{Amplification of genomic DNA}

After informed consent, genomic DNA was prepared, by standard methods, from patients' peripheral blood leukocytes and/or cultured skin fibroblasts and used for the subsequent studies. PCR reactions were conducted in 25$\mu \mathrm{L}$ reaction volumes containing approximately $100 \mathrm{ng}$ genomic DNA, $1 \times \mathrm{PCR}$ reaction buffer $\left(50 \mathrm{mmol} \mathrm{L}^{-1}\right.$ $\mathrm{KCl}, 10 \mathrm{mmol} \mathrm{L}{ }^{-1}$ Tris- $\mathrm{HCl}$ ), $1.5 \mathrm{mmol} \mathrm{L}^{-1} \mathrm{MgCl}_{2}$, $0.2 \mathrm{mmol} \mathrm{L}^{-1} \mathrm{dNTP}, 0.2 \mu \mathrm{mol} \mathrm{L}{ }^{-1}$ of each primer, and $1.25 \mathrm{U}$ Taq DNA polymerase (Promega, Madison, USA). The thermal profile consisted of initial denaturation at $95^{\circ} \mathrm{C}$ for $5 \mathrm{~min}$, followed by 35 cycles at $95^{\circ} \mathrm{C}$ for $1 \mathrm{~min}, 51^{\circ} \mathrm{C}$ for $1 \mathrm{~min}$, and $72^{\circ} \mathrm{C}$ for $2 \mathrm{~min}$, with a final extension at $72^{\circ} \mathrm{C}$ for $7 \mathrm{~min}$. Each PCR mixture $(5 \mu \mathrm{L})$ was run on agarose gel to ensure that only the specific product was amplified. Seventeen pairs of primer sequences for amplication of exons and exon-intron boundaries of GALC gene are listed Table 2.

Screening for 12Del3Ins and I66M + I289V

by restriction enzyme digestion

For screening of 12Del3Ins (635-646del/insCTC resulting in 212-216 del(NLWES)/ins(TP)), a previously reported and relatively common mutation (Tatsumi et al. 1995; Fu et al. 1999), genomic DNA samples were amplified with the primer pair of exon 7 and the product was digested with HinfI (Fig. 1a). I66M + I289V, first reported by Furuya et al. (1997), is a unique mutation identified in the Japanese population. Only when two single-nucleotide substitutions (I66M, I289V) resided on the same allele was their combination $(\mathrm{I} 66 \mathrm{M}+\mathrm{I} 289 \mathrm{~V})$ proved to be a pathogenic mutation (Furuya et al. 1997). To detect I66M $(198 \mathrm{~A}>\mathrm{G})$, genomic DNA samples were amplified using a sense primer of exon 2 (Table 2) and a mismatch-antisense primer (5'-TCATTACCTTAAAGAGATAATCCGA-3'). The product was digested with EcoRV (Fig. 1b). To detect I289V (865A $>$ G), genomic DNA samples were amplified with a sense primer of exon 9 (Table 2) and a mismatch-antisense primer (5'-ACTAGCCACTAAATTCCAGTCGA-3') and product was digested with SalI (Fig. 1c). All the digested fragments were subjected to electrophoresis in 3\% NuSieve 3:1 agarose gel (BioWhittaker Molecular Applications, Rockland, ME, USA). The PCR amplification of three fragments was performed under the same conditions described above. When both I66M and I289V were heterozygous in a patient, mutation analysis of the patient's parents with screening for I66M and I289V was necessary to clarify whether I66M and I289V resided on the same allele. For all observed digestion patterns different from the normal control, the corresponding fragments were re-amplified for direct sequencing analysis.

Screening for the $30 \mathrm{~kb}$ large deletion mutation

To screen for the $30 \mathrm{~kb}$ deletion mutation, a previously reported and common mutation in Caucasians, genomic DNA samples were amplified using three primers in accordance with the method described by Luzi et al. (1995).

Denaturing high performance liquid chromatography (DHPLC)

For patients A1-A11, all of the 17 exons and exon-intron boundaries were amplified by polymerase chain reaction (PCR) as described above. DHPLC analysis was performed with the Wave DNA fragment analysis system equipped with a DNASep Column (Transgenomic Omaha, NE, USA). Before mutation analysis the PCR products for each exon were denatured at $94^{\circ} \mathrm{C}$ for $5 \mathrm{~min}$, followed by gradual re-annealing at $94-25^{\circ} \mathrm{C}$ over $45 \mathrm{~min}$ to enable formation of heteroduplexes. All samples were run at three different oven temperatures, listed in Table 2. PCR-amplified products with a heteroduplex profile were re-amplified and used for direct sequencing analysis.

\section{Reverse-transcription PCR and direct sequencing}

For patients with no mutations or only one mutation by common mutation screening or DHPLC, GALC mutation analysis was performed by sequencing cDNA. Total RNA was extracted from cultured skin fibroblasts or lymphocytes and first-strand cDNA synthesis was performed with MMLV reverse transcriptase (Gibco BRL) according to the manufacturer's recommendations. The coding region was amplified by PCR in two overlapping fragments from first-strand cDNA, as described elsewhere ( $\mathrm{Fu}$ et al. 1999). PCR products were directly sequenced using the BigDye Terminator V1.1 cyclesequencing kit (Applied Biosystems, Warrington, UK) and the Applied Biosystems 3730 DNA analyzer.

Screening for S257F and L364R in healthy individuals

To screen for two novel missense mutations (S257F, L364R), PCR amplification of genomic DNA from 100 
Table 1 Summary of clinical information and mutations identified in Japanese patients with Krabbe disease

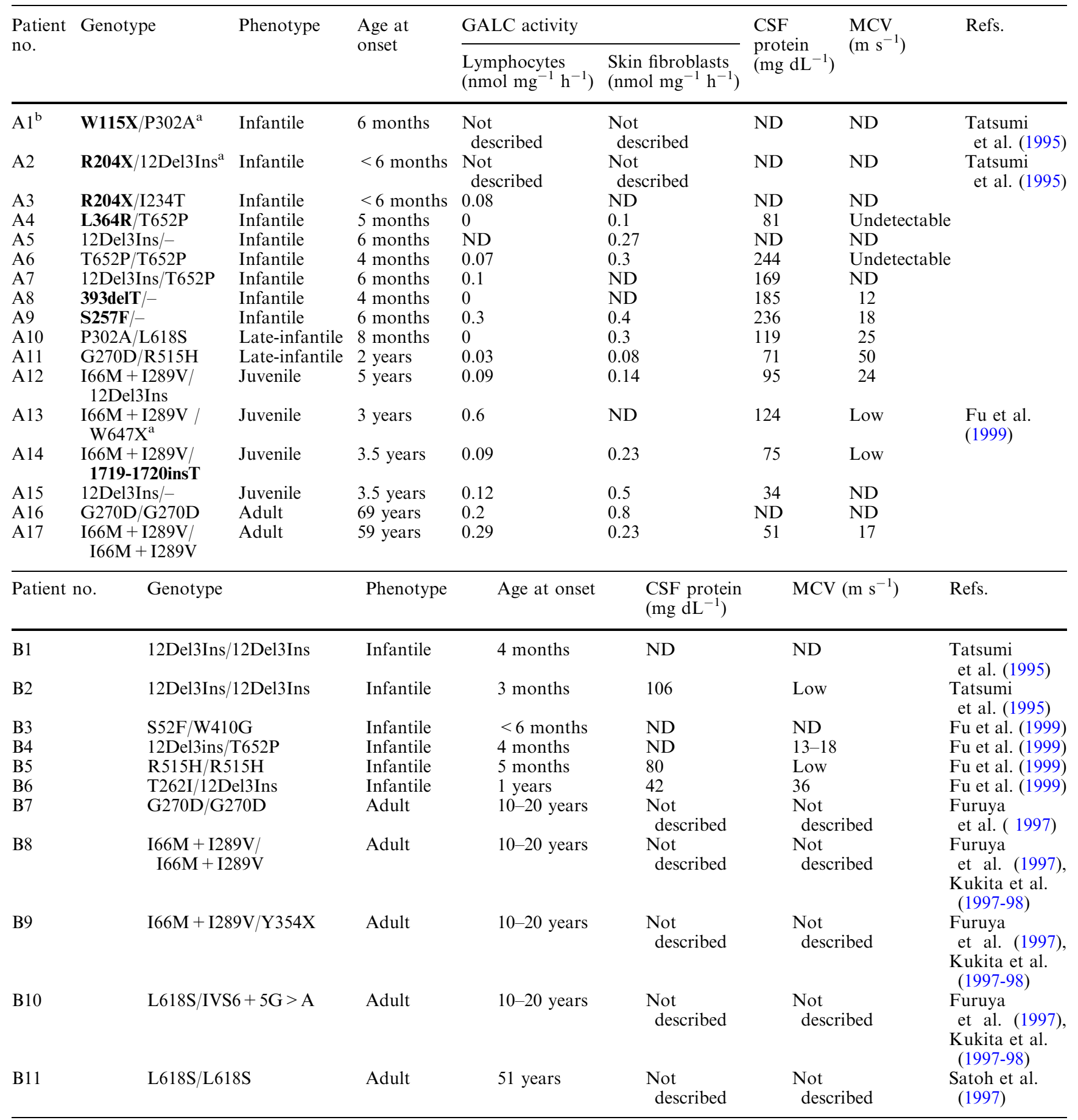

Bold print in Genotype column denotes a novel mutation identified in this study

Normal ranges of GALC activity in lymphocytes and skin fibroblasts are $2.1 \pm 0.29$ and $4.5 \pm 1.2 \mathrm{nmol} \mathrm{mg}^{-1} \mathrm{~h}^{-1}$, respectively

"A" in patient no. column represents the subjects investigated in this study; "B" in patient no. column represents subjects reported previously

"_" in the Genotype column indicates no mutation was found in the second allele in our experiment

CSF cerebrospinal fluid, MCV motor nerve conduction velocity, ND not done

${ }^{\text {a }}$ Previously detected mutant allele

${ }^{\mathrm{b}}$ The patient was previously reported as late-infantile type. This has, however, been corrected to infantile type on the basis of detailed clinical information 
Table 2 Primer sequences used for PCR amplification of GALC gene, and DHPLC oven temperatures

\begin{tabular}{llllll}
\hline Exon & Forward primer $\left(5^{\prime}>3^{\prime}\right)$ & Reverse primer $\left(5^{\prime}>3^{\prime}\right)$ & $\begin{array}{l}\text { Size } \\
(\text { bp })\end{array}$ & $\begin{array}{l}\text { Predicted } \\
\text { temperature }\left({ }^{\circ} \mathrm{C}\right)\end{array}$ & $\begin{array}{l}\text { DHPLC oven } \\
\text { temperature }\left({ }^{\circ} \mathrm{C}\right)\end{array}$ \\
\hline 1 & GGAGTCATGTGACCCACACA & CGCGTATCCCCGCAGCTT & 242 & 56 & $55 / 56 / 57$ \\
2 & GGTGTGCGTGAACACTGTAGA & CTATGGTGAAATTCACCATCC & 215 & 54.8 & $54 / 55 / 56$ \\
3 & GGATGGTGAATTCACCATAG & TCACAGTCCATATGCTGAGGT & 333 & 54.9 & $54 / 55 / 56$ \\
4 & GGTCCTAGGAAGTACCATTCATG & CACCAACACGATTCAGAATTTA & 190 & 56.4 & $55 / 58 / 61$ \\
5 & GTTTTATTTCAATAGCGCCAGC & CCTCATGGCATAAAATGGTTAGC & 312 & 57 & $55 / 57 / 59$ \\
6 & AATGGTATCGTAACGATAATCTG & TTTCTGTGTTAGGACCATAAGG & 190 & 54.5 & $54 / 55 / 56$ \\
7 & CTATTATCCAGAACGCTGATTTG & GTAATCAAATGGGGAGAAGGC & 335 & 54.4 & $53 / 55 / 56$ \\
8 & GAAAACCTTGGAGAAGACTCGTA & GGCTGGAAGAATAAGGAATCC & 354 & 53.2 & $54 / 56 / 58$ \\
9 & CTCCAGGTTTTAGACATTTAC & CTGCTTTGTCTCTTAGAGAAGA & 251 & 55.7 & $52 / 55 / 58$ \\
10 & CAGACTCAAATTGATATACAGCT & GGCATCTGTCTGTATGCTTAT & 337 & 53.1 & $54 / 56 / 58$ \\
11 & TTCTGTTAATCTTGGGCATTAAC & CAGGGCCTCTGTCAATTCATA & 317 & 54.4 & $54 / 54 / 56$ \\
12 & CATTGGTACATTCTTGCTGGTACT & GTCACCATCCACCAAGACAAA & 413 & 54.5 & $53.5 / 54.5 / 56.5$ \\
13 & ATTCCAAGGGCCTTGATATTG & TTTGACAGCCACTCCATCATG & 413 & 55.7 & $54 / 56 / 60$ \\
14 & AATATCAGCAAGGAGAGCTTCTG & GGAGGACCATTGAAAACTCTTC & 339 & 56.7 & $54 / 56 / 58$ \\
15 & GCATGTGCTGTGAAATGACATA & CCCACAAATAACAAGTAGGTGCT & 325 & 55.1 & $55.1 / 56.1 / 57.1$ \\
16 & CAGATGCCACTCAAGAACCCC & CCCCTCCTATTTTATAACAG & 251 & 55.1 & $52 / 54 / 55$ \\
17 & CCATACATGATCAAGAAACAGAC & GAAACAAGAATTGGCTCTGAA & 301 & 57.9 & $56.9 / 57.9 / 58.9$ \\
\hline
\end{tabular}

healthy individuals was performed with the primer pair for exon 8 and exon 10 (Table 2) and the product was digested with Eco 57I and Aci I, respectively. The normal allele of $257 \mathrm{~S}$ should be digested by Eco 57I and the mutant allele of 364R should be digested by $\mathrm{Aci}$ I.

\section{Results}

All 27 mutations detected in this study are listed in Table 1. The analytical procedures for GALC mutation detection are described in detail below.

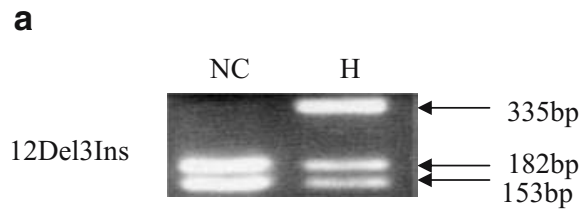

b

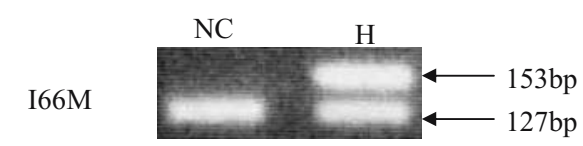

C

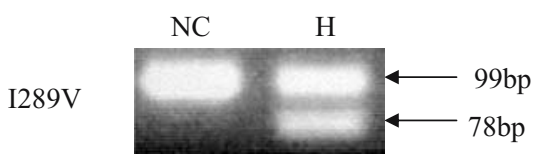

NC: normal control

H: heterozygous

Fig. 1 Mutation detection for 12Del3Ins and I66M + I289V with restriction enzyme digestion. a Genomic DNA samples were amplified with the primer pair of exon 7; the product was digested with HinfI and subjected to $3 \%$ Nusieve gel. Fragments with 12Del3Ins were not digested with HinfI. b For detection of I66M,
Screening for 12 Del3Ins and I66M + I289V with restriction enzyme digestion

DNA isolated from peripheral blood leukocytes or cultured skin fibroblasts was tested for mutation detection. Screening for 12Del3Ins mutation by restriction enzyme digestion revealed that five patients (A2, A5, A7, A12, A15), including one patient (A2) reported previously, were heterozygous. As a result of screening for $\mathrm{I} 66 \mathrm{M}+\mathrm{I} 289 \mathrm{~V}, \mathrm{I} 66 \mathrm{M}$ was found to be homozygous in one patient (A17), heterozygous in three patients (A12, $\mathrm{A} 13$, and A14), and I289V was found to be homozygous
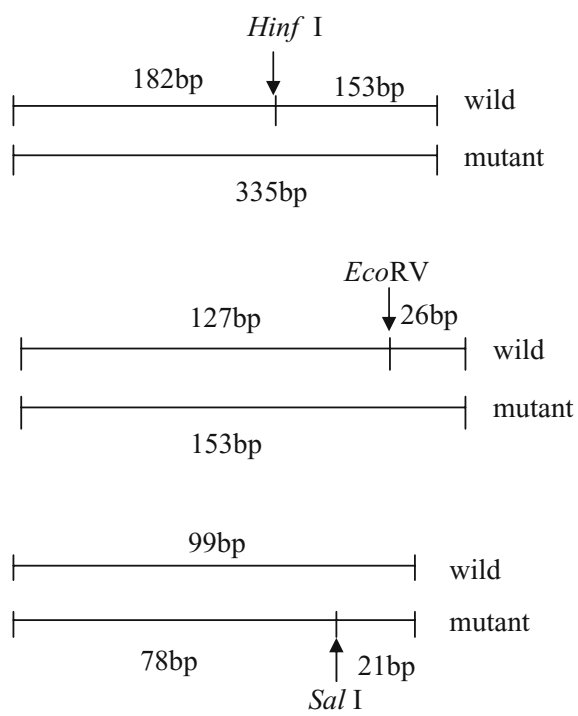

amplified fragments using a sense primer of exon 2 and a mismatchantisense primer (5'-TCATTACCTTAAAGAGATAATCCGA-3') were digested with EcoRV. c To detect I289V, amplified fragments with a sense primer of exon 9 and a mismatch-antisense primer $\left(5^{\prime}\right.$ ACTAGCCACTAAATTCCAGTCGA-3') were digested with SalI 
in A14 and A17, and heterozygous in A12 and A13. In patients 14 and 17 , I66M and I289V were easily confirmed to reside on the same allele. To confirm that I66M and I289V resided on the same allele in patients A12 and A13, their parents' DNA was also analyzed for $\mathrm{I} 66 \mathrm{M}$ and $\mathrm{I} 289 \mathrm{~V}$. In $\mathrm{A} 12$ and $\mathrm{A} 13$, both $\mathrm{I} 66 \mathrm{M}$ and I $289 \mathrm{~V}$ were proved to reside on the same allele inherited from the father of A12 and the mother of A13, respectively. I289V substitution without I66M in patient A14 was regarded as a polymorphism. These mutations were also confirmed by direct sequencing analysis.

Screening for the $30 \mathrm{~kb}$ large deletion mutation

Shortened PCR products from the deleted allele were not detected in any of our patients. The most frequent mutation in Caucasians was not found in our Japanese patients.

Mutation screening with DHPLC and mutation detection with direct sequencing

DHPLC analysis was performed for 11 patients (A111). Seventeen abnormal DHPLC elution profiles (A1, exons 4, 9; A2, exon 7; A3, exon 7; A4, exons 10, 12, 17; A5, exon 7; A7, exons 5, 7, 17; A8, exon 4; A9, exons 14 , 15; A10, exons 9, 16; A11, exon 14) were found. The corresponding amplicons were characterized by direct sequencing. As a result, four polymorphisms (A7, IVS5 + 71G > A; A9, IVS14+60C > T; A4, 1254C > T (S418S); and A9, 1637T $>\mathrm{C}($ I546T)) and 15 mutations (A1, W115X, P302A; A2, R204X, 12Del3Ins; A3, R204X, I234T; A4, L364R, T652P; A5, 12Del3Ins; A7, 12Del3Ins, T652P; A8, 393delT; A10, P302A, L618S; A11, R515H) were identified in the above 17 amplicons by direct sequencing. Within four polymorphisms, two $(\mathrm{IVS} 5+71 \mathrm{G}>\mathrm{A}$ and IVS14 $+60 \mathrm{C}>\mathrm{T})$ were novel intronic polymorphisms and the other two $(1254 \mathrm{C}>\mathrm{T}$ (S418S) and 1637T $>C$ (I546T)) were exonic polymorphisms which have previously been reported (Sakai et al. 1994; Kukita et al. 1997-98). Within 15 mutations, 11 mutations were first identified by DHPLC; the exceptions were two mutations (A1, P302A; A2, 12Del3Ins) identified in the previous study (Tatsumi et al. 1995) and two mutations (A5, A7, 12Del3Ins) already detected in the screening step for 12Del3Ins. Four different novel mutations (W115X, R204X, L364R, and 393delT) were found in this step.

\section{Reverse-transcription PCR and direct sequencing}

Two mutations were identified in nine patients (A1, 2, 3, $4,7,10,12,13,17)$ by use of the screening methods described above. Only one mutation (12Del3Ins, 393delT, R515H, I66M + I289V, and 12Del3Ins) was found in five patients (A5, 12Del3Ins; A8, 393delT; A11,
$\mathrm{R} 515 \mathrm{H} ; \mathrm{A} 14, \mathrm{I} 66 \mathrm{M}+\mathrm{I} 289 \mathrm{~V} ; \mathrm{A} 15,12 \mathrm{Del}$ Ins). In the remaining three patients $(\mathrm{A} 6,9,16)$, no mutations were found. To identify other mutations, mutation analysis by RT-PCR and direct sequencing were performed for eight patients (A5, 6, 8, 9, 11, 14, 15, 16), and four different mutations, the exceptions being the mutations detected by use of the above methods, were detected in five patients (T652P homozygous in A6, S257F heterozygous in A9, G270D heterozygous in A11, 17191720ins Teterozygous in A14, and G270D homozygous in A16). In patient A14, I289V was also confirmed on the same allele as $1719-1720 \mathrm{insT}$; I289V is regarded as a polymorphism, however, because substitution of I289V without I66M has been proven to be polymorphism (Furuya et al. 1997) and the 1719-1720insT resulted in frame shift leading to a premature stop codon. Two mutations (S257F and 1719-1720insT) were novel. These mutations were also confirmed by direct sequencing of genomic DNA.

Screening for S257F and L364R in healthy individuals

Of the six novel mutations (W115X, R204X, S257F, L364R, 393delT, and 1719-1720insT), two missense mutations (S257F, L364R) were screened by restriction enzyme digestion. These mutations were not detected in 100 healthy controls.

\section{Genotype-phenotype correlation}

The detected mutations are summarized in Table 1 with reference to reported mutations in Japanese patients. Table 1 includes other clinical information about the patients. Fourteen different mutations identified in this study were found in 27 detected alleles of 17 patients, including nine missense mutations (I66M + I289V, I234T, S257F, G270D, P302A, L364R, L618S, T652P), two nonsense mutations (W115X and R204X), one small deletion (393delT), one small insertion (17191720T), and one deletion/insertion (12Del3Ins). Of these mutations, six were novel (W115X, R204X, S257F, L364R, 393delT, and 1719-1720insT). All GALC mutations in Japanese patients, with their frequencies, including those previously reported, are summarized in Table 3.

The distribution of the clinical phenotype for each mutation is summarized in Table 4. For rare mutations, those detected less than twice, the genotype-phenotype correlation remains indeterminate; for rather common mutations, however, the tendency between genotype and phenotype was observed. The phenotype for 12Del3Ins, T652P, and $\mathrm{R} 515 \mathrm{H}$ was observed mostly in infantiletype Krabbe disease whereas I66M + I289V, G270H, and L618S were mostly detected in the adult type and never in the infantile form of the disease. Concerning the regional distribution of patients, there was no specific region for each mutation. 
Table 3 Summary of mutations identified in 28 Japanese patients including 11 patients previously characterized

Bold print denotes novel mutations identified in this study. "fs" indicates a frameshift starting after the respective codon

\begin{tabular}{|c|c|c|c|c|c|}
\hline No. & Exon/intron & Nucleotide change & Amino acid change & $\begin{array}{l}\text { Allele } \\
\text { frequency }\end{array}$ & $\begin{array}{l}\text { Allele } \\
\text { number }\end{array}$ \\
\hline 1 & 2 & $198 \mathrm{~A}>\mathrm{G}+865 \mathrm{~A}>\mathrm{G}$ & $\mathrm{I} 66 \mathrm{M}+\mathrm{I} 289 \mathrm{~V}$ & 0.15 & 8 \\
\hline 2 & 2 & $155 \mathrm{C}>\mathrm{T}$ & S52F & 0.02 & 1 \\
\hline 3 & 4 & $344 G>A$ & W115X & 0.02 & 1 \\
\hline 4 & 4 & 393delT & L130fs; 154X & 0.02 & 1 \\
\hline 5 & IVS6 & IVS $6+5 \mathrm{G}>\mathrm{A}$ & 179-191 skipping & 0.02 & 1 \\
\hline 6 & 7 & $610 \mathrm{C}>\mathrm{T}$ & R204X & 0.04 & 2 \\
\hline 7 & 7 & $\begin{array}{l}\text { 635-646 del/ins } \\
\text { CTC (12Del3Ins) }\end{array}$ & $\begin{array}{l}212-216 \text { del } \\
\text { (NLWES)/ins (TP) }\end{array}$ & 0.22 & 11 \\
\hline 8 & 7 & $701 \mathrm{~T}>\mathrm{C}$ & $\mathrm{I} 234 \mathrm{~T}$ & 0.02 & 1 \\
\hline 9 & 8 & $770 \mathrm{C}>\mathrm{T}$ & S257F & 0.02 & 1 \\
\hline 10 & 8 & $785 \mathrm{C}>\mathrm{T}$ & T262I & 0.02 & 1 \\
\hline 11 & 8 & $809 \mathrm{G}>\mathrm{A}$ & G270D & 0.1 & 5 \\
\hline 12 & 9 & $904 \mathrm{C}>\mathrm{G}$ & P302A & 0.04 & 2 \\
\hline 13 & 10 & $1062 \mathrm{C}>\mathrm{G}$ & Y354X & 0.02 & 1 \\
\hline 14 & 10 & $1091 \mathrm{~T}>\mathrm{G}$ & L364R & 0.02 & 1 \\
\hline 15 & 12 & $1228 \mathrm{~T}>\mathrm{G}$ & W410G & 0.02 & 1 \\
\hline 16 & 14 & $1544 \mathrm{G}>\mathrm{A}$ & R515H & 0.06 & 3 \\
\hline 17 & 15 & 1719-1720insT & R574X & 0.02 & 1 \\
\hline 18 & 16 & $1853 \mathrm{~T}>\mathrm{C}$ & L618S & 0.08 & 4 \\
\hline 19 & 17 & $1941 G>A$ & W647X & 0.02 & 1 \\
\hline 20 & 17 & $1954 \mathrm{~A}>\mathrm{C}$ & $\mathrm{T} 652 \mathrm{P}$ & 0.1 & 5 \\
\hline Total & & & & 1 & 52 \\
\hline
\end{tabular}

\section{Discussion}

In this work we detected 27 mutant alleles in 17 patients. We found six novel mutations of the GALC gene in Japanese patients with Krabbe disease. Two, W115X and R204X, were nonsense mutations whereas 393delT and 1719-1720insT resulted in frame shifts. It was obvious all four were pathogenic mutations. The final two, S257F and L364R, were missense mutations that were not detected in 100 healthy controls. These two loci

Table 4 Correlation between genotype and phenotype in 28 Japanese subjects

\begin{tabular}{lllllr}
\hline Mutation & Infantile & Late-infantile & Juvenile & Adult & $\begin{array}{r}\text { Total } \\
\text { allele }\end{array}$ \\
\hline 12Del3Ins & 9 & 0 & 2 & 0 & 11 \\
T652P & 5 & 0 & 0 & 0 & 5 \\
R515H & 2 & 1 & 0 & 0 & 3 \\
R204X & 2 & 0 & 0 & 0 & 2 \\
P302A & 1 & 1 & 0 & 0 & 2 \\
S52F & 1 & 0 & 0 & 0 & 1 \\
W115X & 1 & 0 & 0 & 0 & 1 \\
393delT & 1 & 0 & 0 & 0 & 1 \\
I234T & 1 & 0 & 0 & 0 & 1 \\
S257F & 1 & 0 & 0 & 0 & 1 \\
T262I & 1 & 0 & 0 & 0 & 1 \\
L364R & 1 & 0 & 0 & 0 & 1 \\
W410G & 1 & 0 & 0 & 0 & 1 \\
1719-1720insT & 0 & 0 & 1 & 0 & 1 \\
W647X & 0 & 0 & 1 & 0 & 1 \\
IVS6+5G $>$ A & 0 & 0 & 0 & 1 & 1 \\
Y354X & 0 & 0 & 0 & 1 & 1 \\
I66M + I289V & 0 & 0 & 3 & 5 & 8 \\
G270H & 0 & 1 & 0 & 4 & 5 \\
L618S & 0 & 1 & 0 & 3 & 4 \\
Total allele & 27 & 4 & 7 & 14 & 52 \\
\hline
\end{tabular}

are well conserved in different species, including monkey, dog, and mouse (Luzi et al. 1997). This evidence, when taken together, suggests that these two missense mutations may be regarded as causative of Krabbe disease.

In four patients, only one mutant allele was detected. Because our screening method covered the coding region and the exon-intron boundary, undetected mutations may lie outside the analyzed region, for example in promoter and enhancer regions. We also did not analyze large-scale genomic rearrangement, other than the screened $30 \mathrm{~kb}$ deletion.

As reported in the literature, mutations of the GALC gene in Krabbe disease are very heterogeneous. In Caucasians, the $30 \mathrm{~kb}$ large deletion reported by Rafi et al. (1995) and Luzi et al. (1995) was widespread within the patient population, having a frequency of $40-50 \%$. Other mutations followed heterogeneous patterning. As in Caucasians, to date, examination of Japanese patients revealed 14 mutations with a very heterogeneous distribution. It was considered hard to screen the GALC mutation, because there is no common mutation in Japanese patients; as our results show, however, there are several common mutations. The most common mutation in Japanese patients is 12Del3Ins with a 0.22 allele frequency. The second most frequent mutation, $\mathrm{I} 66 \mathrm{M}+\mathrm{I} 289 \mathrm{~V}$, has 0.15 prevalence. To date, these two mutations have been identified in Japanese patients only. These two mutations are also unique and difficult to conceive as recurrently occurring mutations. They might be derived from a founder; parents' samples necessary for haplotype analysis were unavailable from most of the families, however.

Referring to Tables 1 and 4, the most common mutation (12Del3Ins) and the two other mutations 
(T652P and $\mathrm{R} 515 \mathrm{H})$ in the homozygous state $(\mathrm{B} 1, \mathrm{~B} 2$, $\mathrm{A} 6$, and $\mathrm{B} 5$ ) resulted in the classic infantile phenotype. The second most common mutation, I $66 \mathrm{M}+\mathrm{I} 289 \mathrm{~V}$, contributed to late-onset-type Krabbe disease, because the homozygous state of this mutation was found only in the adult type (patients A17 and B8), the mildest form of the disease, whereas the heterozygous state was detected in the juvenile or adult form (patients A12, A13, A14, and B9). This concordance strongly suggests that the existence of this mutation leads to the mild clinical phenotype. Because screening for this mutation might directly reveal a mild phenotype of Krabbe disease in Japanese patients, we propose a viable screening method using restriction enzyme digestion with PCR fragments for I66M (Fig. 1b) and I289V (Fig. 1c). For the missense mutations G270D and L618S, similar concordance is shown in Tables 1 and 4, demonstrating that it will be effective to screen for this mutation to estimate the mild phenotype.

For most enzyme-deficiency diseases it is generally believed there is a correlation between residual enzyme activity and clinical severity; this does not appear to be true for Krabbe disease, however. The expression experiment did not always reveal better residual activity in late-onset patients. Harzer et al. (2002) analyzed substrate specificity for several mutations and, although the G270D mutation led to loss of enzymatic activity for galactocerebroside as its natural substrate, nearly normal activity for psychosine, its second substrate, was preserved. This paper supports the idea that measurement enzyme activity with one substrate does not necessarily lead to identification of an essential defect. It might be important to analyze the substrate specificity of L618S and I66M + I289V to elucidate genotype-phenotype correlation.

In a previous study, Furuya et al. (1997) investigated $\mathrm{I} 66 \mathrm{M}+\mathrm{I} 289 \mathrm{~V}$ allele expression, and found reduced enzymatic activity only when these two amino acid changes occurred on the same allele. We likewise confirmed that I66M and I289V occurred on the same strand and same peptide in all four patients. That I66M and $\mathrm{I} 289 \mathrm{~V}$ reside on the same strand suggests that each amino acid contributes to a different function, for example reaction center or substrate binding. Analysis of the structure of the crystallized protein might be important for future understanding of the mechanism of this mutation.

Acknowledgements This work was supported by grants from the Ministry of Education, Science, Sports and Culture of Japan and the Health and Labor Science Research.

\section{References}

Chen YQ, Rafi MA, de Gala G, Wenger DA (1993) Cloning and expression of cDNA encoding human galactocerebrosidase, the enzyme deficient in globoid cell leukodystrophy. Hum Mol Genet 2:1841-1845

Fu L, Inui K, Nishigaki T, Tatsumi N, Tsukamoto H, Kokubu C, Muramatsu T, Okada S (1999) Molecular heterogeneity of Krabbe disease. J Inherit Metab Dis 22:155-162

Furuya H, Kukita Y, Nagano S, Sakai Y, Yamashita Y, Fukuyama H, Inatomi Y, Saito Y, Koike R, Tsuji S, Fukumaki Y, Hayashi K, Kobayashi T (1997) Adult onset globoid cell leukodystrophy (Krabbe disease): analysis of galactosylceramidase cDNA from four Japanese patients. Hum Genet 100:450-456

Harzer K, Knoblich R, Rolfs A, Bauer P, Eggers J (2002) Residual galactosylsphingosine (psychosine) beta-galactosidase activities and associated GALC mutations in late and very late onset Krabbe disease. Clin Chim Acta 317:77-84

Krabbe K (1916) A new familial, infantile form of diffuse brain sclerosis. Brain 39:74-114

Kukita Y, Furuya H, Kobayashi T, Sakai N, Hayashi K (1997-98) Characterization of the GALC gene in three Japanese patients with adult-onset Krabbe disease. Genet Test 1:217-223

Luzi P, Rafi MA, Wenger DA (1995) Characterization of the large deletion in the GALC gene found in patients with Krabbe disease. Hum Mol Genet 4:2335-2338

Luzi P, Rafi MA, Victoria T, Baskin GB, Wenger DA (1997) Characterization of the rhesus monkey galactocerebrosidase (GALC) cDNA and gene and identification of the mutation causing globoid cell leukodystrophy (Krabbe disease) in this primate. Genomics 42:319-324

Rafi MA, Luzi P, Chen YQ, Wenger DA (1995) A large deletion together with a point mutation in the GALC gene is a common mutant allele in patients with infantile Krabbe disease. Hum Mol Genet 4:1285-1289

Sakai N, Inui K, Fujii N, Fukushima H, Nishimoto J, Yanagihara I, Isegawa Y, Iwamatsu A, Okada S (1994) Krabbe disease: isolation and characterization of a full-length cDNA for human galactocerebrosidase. Biochem Biophys Res Commun 198:485491

Satoh JI, Tokumoto H, Kurohara K, Yukitake M, Matsui M, Kuroda Y, Yamamoto T, Furuya H, Shinnoh N, Kobayashi T, Kukita Y, Hayashi K (1997) Adult-onset Krabbe disease with homozygous T1853C mutation in the galactocerebrosidase gene. Unusual MRI findings of corticospinal tract demyelination. Neurology 49:1392-1399

Tatsumi N, Inui K, Sakai N, Fukushima H, Nishimoto J, Yanagihara I, Nishigaki T, Tsukamoto H, Fu L, Taniike M, Okada S (1995) Molecular defects in Krabbe disease. Hum Mol Genet 4:1865-1868

Wenger DA, Rafi MA, Luzi P (1997) Molecular genetics of Krabbe disease (globoid cell leukodystrophy): diagnostic and clinical implications. Hum Mutat 10:268-279

Wenger DA, Suzuki Ku, Suzuki Y, Suzuki Ki (2001) Galactosylceramide lipidosis: globoid cell leukodystrophy (Krabbe disease). In: Scriver CR, Beaudet AL, Sly WS,Valle D (eds) The metabolic and molecular bases of inherited disease. McGrawHill, New York, pp 3669-3694 